IFAS Extension

\title{
Alimentación Saludable: ¡Organice Su Plato! ${ }^{1}$
}

Jennifer Hillan and Linda B. Bobroff ${ }^{2}$

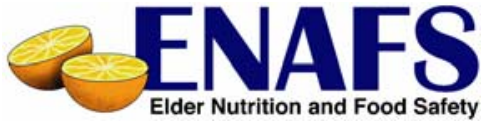

Planear sus comidas puede ayudarle a controlar los tamaños de porciones y la cantidad de carbohidratos que usted consuma a través del día. Esto es especialmente importante si usted padece de la diabetes o si usted es una persona en alto riesgo de padecer de la diabetes. ¡Empecemos!

\section{Usted Va a Necesitar...}

Un plato de nueve pulgadas (mida su plato para ensalada o la cena) Un tazón con capacidad para $1 / 2$ taza de frutas Un tazón con capacidad para 1 taza de caldo o cereal

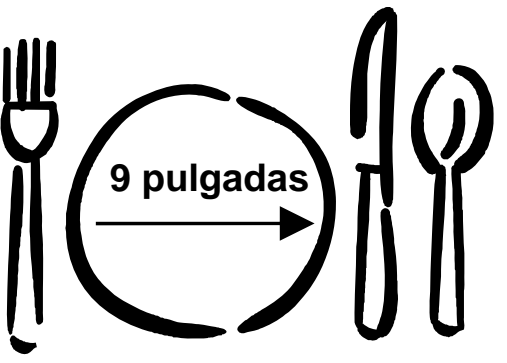

\section{Llene Su Plato Con...}

$1 / 2$ plato $=$ vegetales no feculentos

$1 / 4$ plato $=$ pan/granos/fideos/arroz/vegetales feculentos

$1 / 4$ plato $=$ carne $/$ pescado/aves/frijoles/huevos

\section{Agregue a Su Plato...}

Una fruta pequeña (o $1 / 2$ taza de fruta picada) Un taza de leche o yogur bajo en grasa

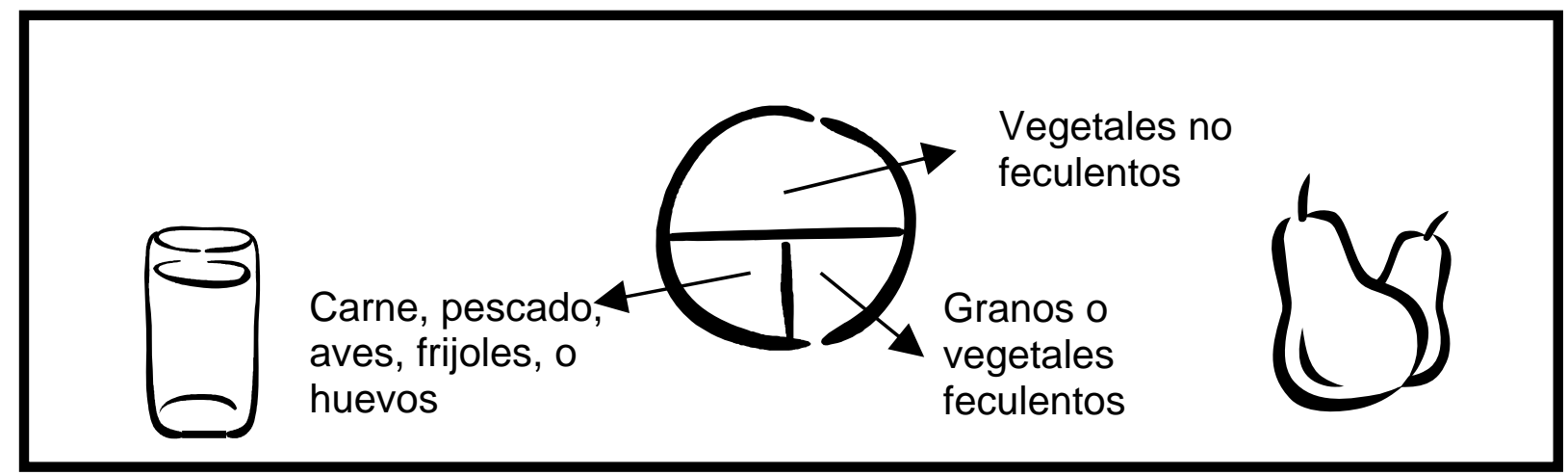

1. The English version of this Spanish document is Healthy Eating: Create Your Plate (FCS8796). Este documento, FCS8796-SPAN, pertenece a una serie del Departamento de Ciencias de la Familia, Juventud y Comunidad, Servicio de Extensión Cooperativo de la Florida, Instituto de Alimentos y Ciencias Agrícolas, Universidad de la Florida. Fecha de publicación: diciembre 2006. Favor de visitar el EDIS Web site en el http://edis.ifas.ufl.edu.

2. Jennifer Hillan, MSH, RD, LD/N, educadora/entrenadora, Linda B. Bobroff, PhD, RD, LD/N, profesora, Departamento de Ciencias de la Familia, Juventud y Comunidad, Servicio de Extensión Cooperativo de la Florida, Instituto de Alimentos y Ciencias Agrícolas, Universidad de la Florida, Gainesville, Florida 32611. Traducción por Jessica R. A. Caicedo, Universidad de la Florida.

El Instituto de Alimentos y Ciencias Agrícolas es un empleador que provee Oportunidades Igualitarias, autorizado a proveer investigación, información educativa y otros servicios, únicamente a los individuos e instituciones que operan sin discriminación alguna con relación al credo, color, religión, edad, incapacidad, sexo, orientación sexual, estado civil, nacionalidad, opinión política o afiliaciones. Para más información sobre como obtener otras publicaciones de extensión, comuníquese con la oficina de Servicio de Extensión de su condado. Servicio de Extensión de la Florida / Instituto de Alimentos y Ciencias Agrícolas / Universidad de la Florida / Larry Arrington, Decano. 


\section{Intercambiando las Porciones}

Las frutas, los granos, y la leche tienen el mismo efecto en los niveles de la glucosa en la sangre, entonces usted puede ocasionalmente intercambiar unos de estos alimentos por otro. Por ejemplo, si no quiere una fruta para el desayuno, consuma otro pedazo de tostada. O intercambie su pedazo de tostada por un vaso de leche. Pero recuerde que es importante consumir alimentos de todos los grupos alimentarios para obtener todas las vitaminas y minerales que usted necesita cada día.

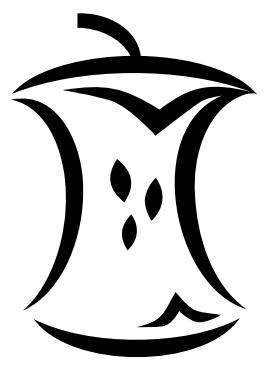

¡Aquí hay algunas sugerencias para empezar!

DESAYUNO
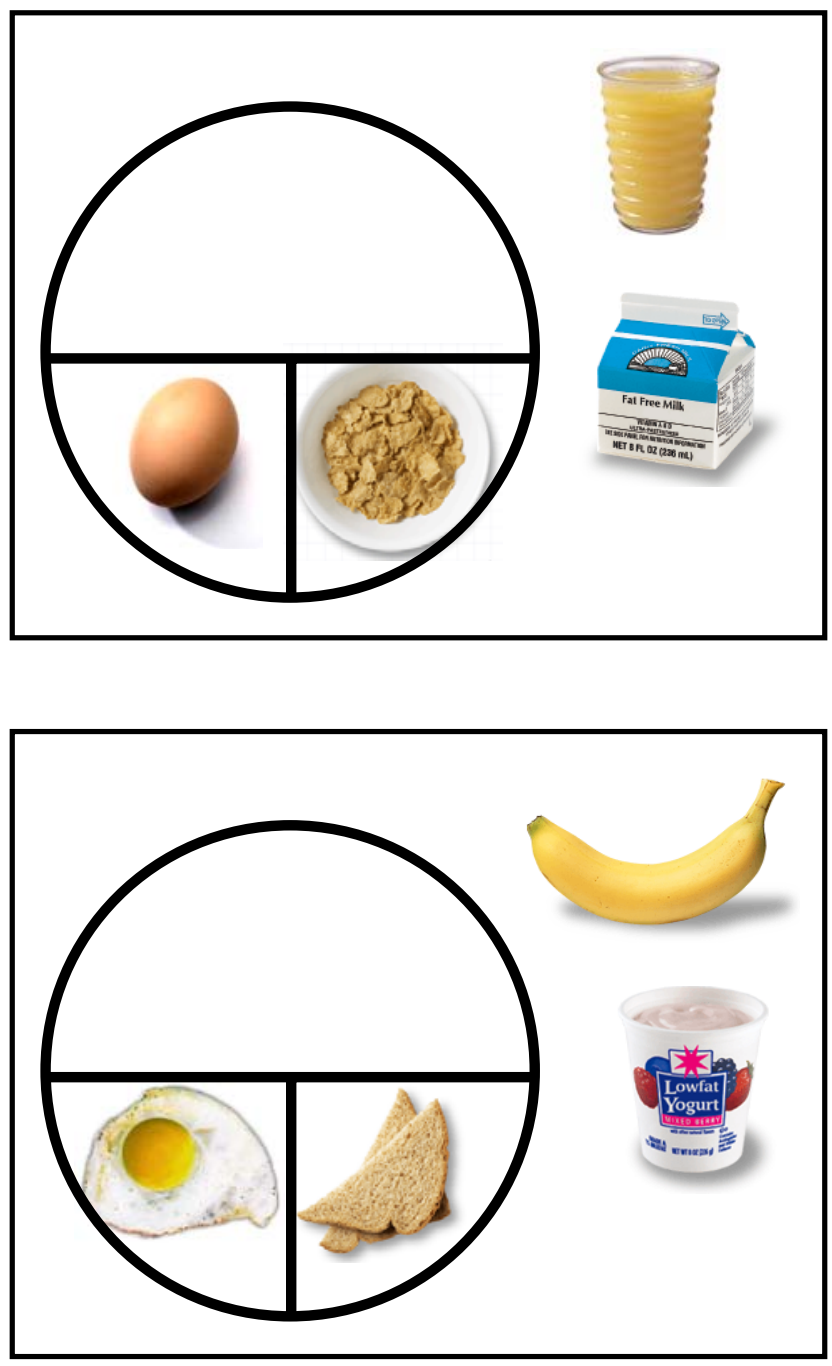

ALMUERZO/CENA
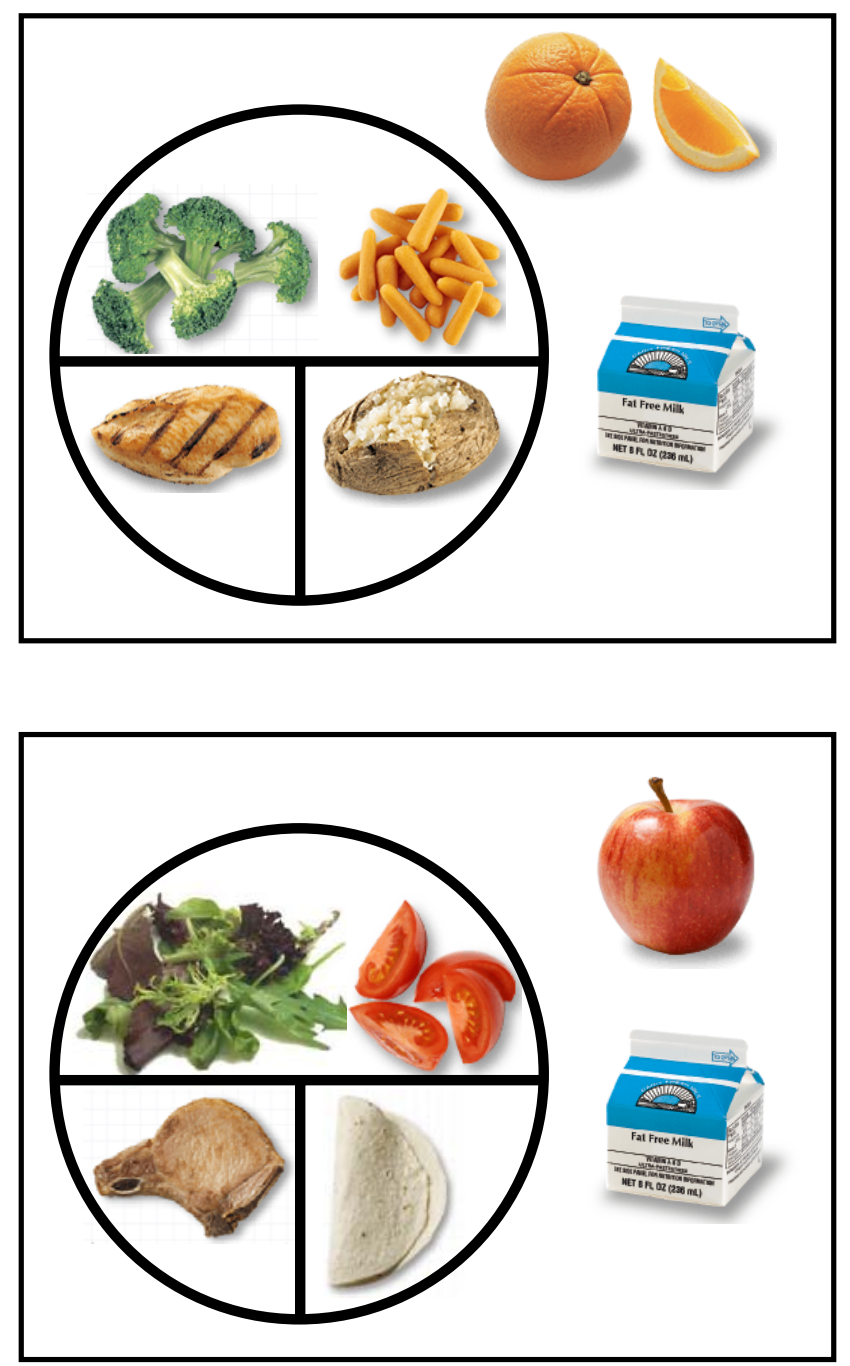

\section{¿Qué decisión hacer con las meriendas y los postres? Si usted quiere una} merienda, guarde su fruta o porción de leche para consumir entre comidas. Si usted quiere un postre pequeño, intercámbielo por su fruta. Pero no haga esto con mucha frecuencia, ya que los postres usualmente son altos en azúcar y calorías. 